\title{
Student Auditing of University Social Responsibility - Reform through Reflective, Experiential Learning?
}

\author{
Coelho, Márcia ${ }^{\text {a }}$; Rodrigues, Fernanda ${ }^{a}$; Evans, Peter ${ }^{\text {b }}$; Menezes, Isabel ${ }^{\text {a }}$ and Brian, \\ Martin $^{c}$ \\ ${ }^{\mathrm{a} C}$ CIIE, FPCE University of Porto, Portugal; ${ }^{\mathrm{b}}$ University of Edinburgh, Scotland; and ${ }^{\mathrm{c}}$ Ergo \\ Consulting
}

\begin{abstract}
The emphasis on the social responsibility of higher education institutions emerged more systematically in the Post-Bologna European context. This paper presents an overview of an ERAMUS + Strategic Partnerships Project on certificate university social responsibility auditing, currently underway in three very different European universities. The overall goal of the Project is to develop auditor training for students based on experiential learning, that is coherent and replicable in diverse contexts and that involves a diverse range of internal and external stakeholders. The project is based on a set of Benchmark Standards for University Social Responsibility developed in the context of an earlier ERASMUS Lifelong Learning project. These Sandards cover four main areas, namely (1) Research, Teaching, Support for Learning and Public Engagement, (2) Governance (3) Environmental and Societal Sustainability; and (4) Fair Practices. In this paper, we will report on the initial data generated by the Project, in respect of student recruitment, baseline attitudes and the impact of participation in the training and the first audit.
\end{abstract}

Keywords: university social responsibility; student training; experiential learning; audit . 


\section{Introduction}

The emphasis on the social responsibility of higher education institutions (HEIs) is frequently assumed as being a relatively recent phenomenon (e.g., Larrán, López \& Márquez, 2011), even if there are references to this role since the early 20th century (e.g., Chase, 1923), and a social purpose of one sort or another is arguably integral to the very nature of higher education and the notion of the "university". A more systematic approach has emerged in the European context, post-Bologna, under the umbrella term of "the social dimension". Nevertheless, one stand of the Bologna Process Implementation Report (2015) has profound implications for "university social responsibility":

"Within the European Higher Education Area, countries have committed to the goal that the student body should reflect the diversity of the populations and that the background of students should not have an impact on their participation in and attainment of higher education.

While some progress can be noted, the analysis clearly shows that the goal of providing equal opportunities to quality higher education is far from being reached." (European

Commission/EACEA/Eurydice, 2015: 19)

The implication of this is that policies and practices that promote equity, justice and democracy in higher education are still a significant challenge.

In this sense, the idea of University Social Responsibility (USR) and the recently developed Benchmark Standards for University Social Responsibility across the EHEA (Martin, 2016) can play a central role not only conceptually, but also in practical terms by guiding intervention efforts in this domain. Recognising the imperatives of widening access to higher education to help ensure that the diversity of European society is reflected in the student population and barriers to entry, progression and attainment are effectively addressed, these Benchmark Standards foreground Research, Teaching, Support for Learning and Public Engagement as the first of four areas within which a European University can be expected to evidence its commitments to social responsibility. This distinctive, sector-specific focus complements the more generic perspective of the International Standards Organisation's ISO 26000, Guidelines on Social Responsibility (2010 and 2012). The three other topics covered in the USR Benchmark Standards are closer to the ISO's concerns though even these (Governance, Environmental and Societal Sustainability and Fair Practices), have been specified in relation to Europe's higher education sector and its distinctive history and nature.

However, the emergent nature of these Standards together with the fact that the rapidly developing field of USR is extremely diverse and prone to conceptual misunderstanding, presents both a need and an opportunity to explore how exactly such Standards might help inform policy and practice in relation to progression and attainment on one hand and the 
growing challenges of - for example - graduate employability on the other. The rest of this paper presents an overview of the current Project that we are all involved with, as a case study of one current exploration of these issues.

\section{A Certificate in University Social Responsibility Auditing}

In a historical analysis of the functions of higher education, Zgaga (2009) identifies four archetypal models that remain relevant in contemporary policy documents (e.g., the 2007 London Communiqué). The Napoleonic model underlines the preparation of students for their future professions; the Humboldtian model values the development of knowledge and research; the Newmanian model accentuates the personal development of students; and Deweyan models focus on promoting community engagement and citizenship. These are not either-or goals of HEIs but rather coexist in both discourses on the role of higher education and in the practices of individual universities.

The ESSA project (http://www.essaproject.eu) funded by European Commission Erasmus+ Programme, reflects this multidimensional vision by involving students as active agents in their universities through a Certificate in Social Responsibility Auditing with focus on University Social Responsibility (USR). The training strand of the Certificate programme and the topic itself accommodate the development of both personal and civic and political competences that should help students maximise the benefits available to them from the later stages of their 1 st cycle studies and from any further study they might undertake, enhance future employability and engage them in a deeper and more productive relationship with both their own university and higher education more broadly. This rationale underpins the development of ESSA in its various components. This Certificate is an elective course that functions as an extra-curricular activity, to be mentioned in the students' diploma supplement in all participating universities and students will have 10 ECTS related to this programme.

The main project objectives are to develop and deliver (i) a facilitator training manual, (ii) a (student) auditor training programme (in blended mode and incorporating experiential and participative action learning in a social responsibility audit of the 'performance' of a university in another European country) and (iii) an assessment scheme with the assessment requirements for the award of a ECTS 10Credit Certificate in Social Responsibility Auditing (http://www.essaproject.eu). The intention is to bring these, the audit guidelines and the various tools, instruments and materials developed in the course of the project together in a substantial Open Educational Resource (OER) that will be grounded in and celebrate reflective experiential learning (e.g., Schon, 1987) as a key to addressing some of the challenges and barriers encountered in addressing the widening access agenda. 
A focal point in both the work of the project itself and in the student/learner's experience will be the latter's participation in one of four audits, which have been conceptualised and are being designed and developed to aid not only individual learning and development but also organisational development for the participating universities.

The project partnership includes the University of Porto, University of Edinburgh, Kaunas University of Technology, and their respective student associations together with the European Students Union (ESU) and the UK's National Union of Student, the project's coordinating partner. Ultimately, the outcomes from the project and the OER itself will be reported to a trans-national European conference to be coordinated by ESU. At that conference, ESU (https://www.esu-online.org) will launch arrangements for the roll-out of the Certificate Programme across the EHEA as a whole.

\subsection{Social Responsibility Audit: Meanings and importance}

Until now, the assessment of universities has "tended to focus solely on the academic aspects of their activities, namely research and teaching. Even the ones which extended the range of dimensions by which to assess universities does not include the dimension of social impact of universities" (Leichsenring, 2016: 2). This gap can be overcome through the social responsibility audit process.

A basic definition of social responsibility auditing would present it as a process that enables an organization to assess and report its performance in relation to society's requirements and expectations, making it more transparent and accountable. Such a review would help to ensure that the organization gives due consideration to its wider social responsibilities, balanced with its own more specific objectives (Gao \& Zang, 2006), beyond a focus on social mobility articulated as enhancing individual employability within competitive labour markets (Williams, 2014).

Thus, a social responsibility audit would help narrow gaps between public policies, societal expectations, institutions vision/ goals and reality through giving voice to all stakeholders, involving them in the process of change (Jain \& Polman, 2003). For Higher Education as a sector, and for Europe's HEIs, this could be a powerful key to successful implementation of the changes required to properly address the estalished and emerging needs, expectations and requirements of society as a whole. Further, it could be a significant means of contributing to realisation of each of the stated goals of the European Commission for its lifelong learning programme: active citizenship, employment and personal fulfilment (European Commission, 2015).

\subsection{Social Responsibility Audit Training as a Focus for Change}

The main focus of the project is the training of student auditors. The high level of engagement proposed for them and the need for raising awareness of participants' own 
agency in both the institutional and wider environments, combined with an introduction to the concepts and skills associated with social responsibility and auditing, are key features of the training. The training rests on the fundamental principles of (i) reflective experiential learning and student-centered approach, (ii) a balance between training and practice experience, with the involvement of students in the direct application of their knowledge and competences in a live, 'for-real' audit and (iii) a social vision of auditing that will foster the transference of learning to participating institutions, but will also enhance students' future employability and citizenship.

Experiential learning is a powerful way to address individual growth and potential, by focusing on the individual learning through experience process - "learning through reflection on doing" (Dewey, 1963). Experiential learning is adaptable for individual style, preferences, strengths, direction, etc. As such, it is more likely than conventional prescribed training or teaching to produce positive effects, notably confidence, and a sense of personal value and purpose. In a student-centred learning approach, the student should be closely involved in the construction of the learning process (rather than getting the 'right' answers), to increase her/his awareness and capacity to identify problems, their causes, and possible solutions.

Student involvement in the audits is also expected to have a significant influence on their development as aware, engaged, critically active citizens and on their own empowerment, as it creates "a suitable framework for the institutionalization of student social involvement and greater social awareness on the part of the institutions themselves." (ESPRIT, 2016). As stakeholders, being part of the university needs to be an experience that enables students to participate successfully in processes or systems not just be taught, study independently and/or collaboratively and produce work for assessment. We will report and comment on the initial data generated by the ESSA Project, in respect of student recruitment, baseline attitudes and the impact of participation in the training and the first audit scheduled to be undertaken in the University of Edinburgh from 24th to 28th of April of 2017.

\subsection{1st cohort of student auditor recruitment and training: initial data}

The first student auditor recruitment and training was developed by the three Universities involved between 3rd March and 19th April. Both recruitment and training were not simultaneous but fulfilled the same structure in terms of guidelines, description, hours of training and learning outcomes.

\subsubsection{Students recruitment}

The student's recruitment was open to third year undergraduate students and above (including masters level students) who had an interest in social responsibility and 
sustainability and fit the student auditor role designed by all the partners and defined as the ideal candidates. The skills and knowledge asked were:

- Good communication skills, both verbal and written, and confidence in face-to-face engagement;

- For international students whose first language is not English, students would have to be fluent in English;

- Confidence to work independently and in a team and able to assist fellow student auditors to identify creative solutions to problems;

- Good analytical and research skills;

- Excellent time management and leadership skills;

- Some knowledge of the workings of universities and and of social responsibility and sustainability issues and initiatives.

In the first cohort of the student audit training there was a total of 32 participants, which included 17 students from University of Porto ${ }^{1}, 6$ from Kaunas University of Technology and 9 from University of Edinburgh with ages raiging from 19 to 35 years, mostly female and from a variety of study areas, as described in Figure 1 and Figure 2.

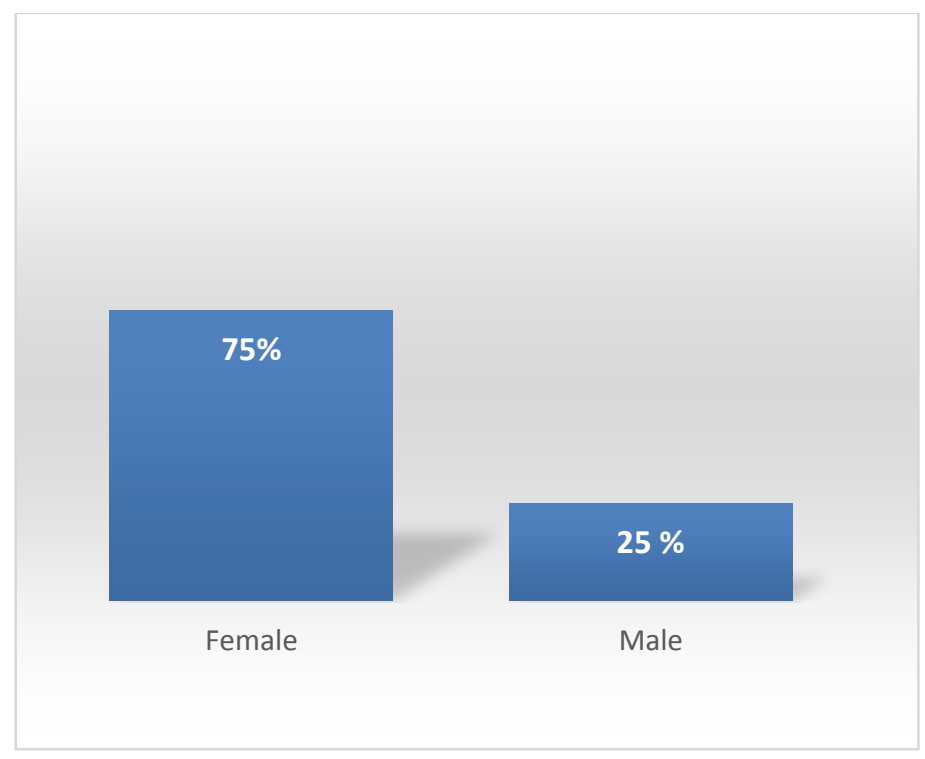

Figure 1. Participants' gender

\footnotetext{
${ }^{1}$ The University of Porto chose to do over recruitment to guarantee the number of students needed for this first and second audits, given the previewed calendar of the second training and its possible interference with the students' final assessment periods.
} 


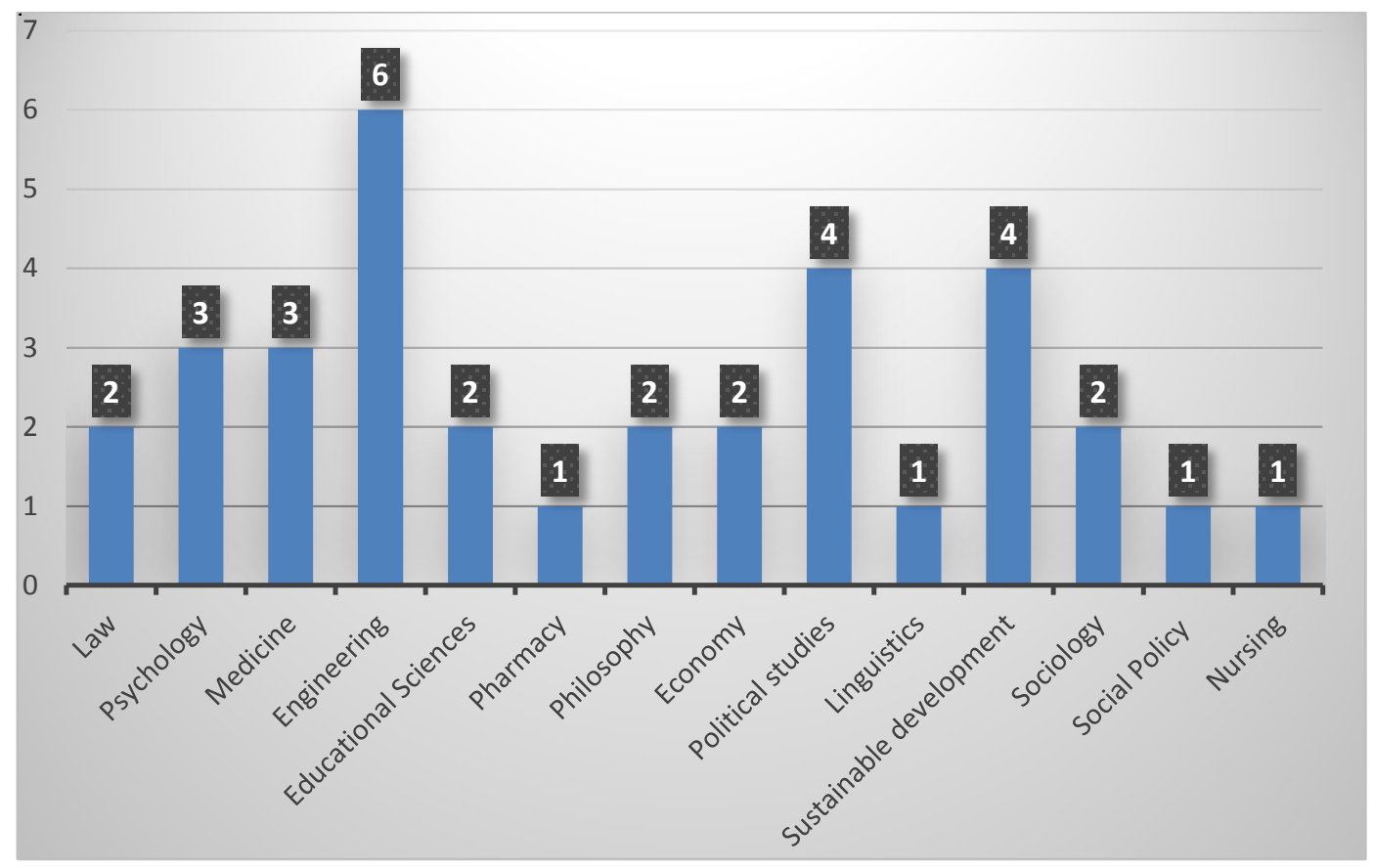

Figure 2 Participants' area of studies

\subsubsection{Students audit training phases}

The Students Audit Training Programme was developed in two parts: a student audit training and the auditing of a university. The three universities completed the 1st part of the training generally the same way in three different, but interconnected, phases:

- Phase 1 comprised the online pre-course, which included a preparatory package with some key readings and videos recommended on the topics of the training in order to prepare a mind-set for the training week and the beginning of an individual training journal, a personal report where the participants were invited to record, on a daily basis, his/her expectations, regarding the training, as well as their individual learning experience.

- Phase 2 was the face-to-face training week, which was divided in three main topics that were considered the most relevant: the USR concept and benchmarking; the Social Responsibility Audit; Simulations of audits and Report. In the beginning of this phase was made the 1st training survey.

- Phase 3 included the online post-course activities, which were self-evaluation activities. 
The second part of the training included conducting a supervised social responsibility audit of a university, is scheduled to be developed in the University of Edinburgh from 24th to 28th of April of 2017, so there is no data from this stage available at the time of writing ${ }^{2}$.

\subsubsection{Student Auditor Training 1st survey: preliminary data}

The 1st part of the student auditor training was completed by all the universities and the 1st training survey questions were subject to content-analysis. The emerging categories relate to motivations, personal learning objectives and expectations. The results of the content analysis are summarized in Tables 1 to 3 . This is followed by a discussion on the key points emerging from this data. The categories in bold characters are those most frequently referred to.

Table 1. Motivations

\begin{tabular}{|l|}
\hline Opportunity to learn more about USR \\
\hline Opportunity to learn more about auditing \\
\hline Opportunity to work in an international/European project \\
\hline Opportunity to acquire/develop new skills \\
\hline My interest in the theme \\
\hline New opportunity for personal development \\
\hline Opportunity to improve my own university \\
\hline Contact with projects/field work \\
\hline Possibility to apply principles/global impact \\
\hline Possibility to work with Sustainability Auditing \\
\hline Being a part of a wider project \\
\hline
\end{tabular}

The participants repeatedly highlighted three different motivations to participate in the project. For some is was the opportunity to learn more about auditing and actually perform audit: "the possibility to apply principles I have learned during lectures to a real-life situation" (Female, UoE); the possibility to learn more about USR: "I am very interested in learning more about University Social Responsibility" (Female, UPorto). For others, it was the opportunity to have the experience of an international project in this area: "To be part of an international project about such an important topic" (Female, UPorto). Other motivations related to the possibility to apply knowledge in the field and the interest for the theme: "The topic itself and the fact that besides the theoretical knowledge the project had also a practical part."(Male, UPorto)

\footnotetext{
${ }^{2} \mathrm{We}$ anticipate being able to share that data in the course of our presentation at the conference however.
} 
Table 2. Personal learning objectives

\begin{tabular}{|l|}
\hline Develop knowledge about social responsibility audit \\
\hline Be able to analyse USR performance \\
\hline Improve analytical and research skills \\
\hline Understanding university social responsibility \\
\hline Understand how universities are managed and work \\
\hline Develop skills in reporting \\
\hline
\end{tabular}

In terms of the learning objectives, all students referred objectives connected with the development of specific skills, whether more general academic skills: "Improve analytical and research skills" (Female, Kaunas) or specificly related with their performance as an auditor in USR: "be able to conduct interviews and focus groups ... as tools to carry out an audit and collect data"(Male, UPorto). Some of them ever go further and relate the personal learning objectives with a larger goal to understand how universities are managed and work and "social responsibility as a social integration strategy" (Female, UoE).

Table 3. Expectations

\begin{tabular}{|l|}
\hline Learn how to audit social responsibility \\
\hline Improve academic/ research skills \\
\hline Get to know other universities reality on social responsibility issues \\
\hline Really audit a university \\
\hline Learn about criteria for assessing sustainability and social responsibility \\
\hline New opportunities \\
\hline Get useful knowledge for academic studies and participation in university \\
\hline
\end{tabular}

After the first part of the training, the students stated that they expected to match some of their personal learning objectives and their motivations (skills development, learn more about the audit USR process) to the possibility of knowing how USR issues are put into practice in other European universities: "I am looking forward to observing how universities of different countries may use different approaches to pursue social responsibility as well as uncovering the underlying factors of these variations" (Female, $\mathrm{UoE})$.

\section{Conclusion}

Assuming that active citizenship needs to be learned in practice and that "educational institutions need to teach systematically how to participate in society" (Leichsenring, 2016 :1), the USR audit training aims to empower students as critical agents of social responsibility in a way that helps facilitate a fundamental redistribution of rights (Frazer, 
1998) in Europe's HEIs, in addition to improving and enhancing the student experience itself and addressing challenges to progression and attainment.

From the first survey, it appears that students also valued this aspect and welcomed the opportunities to work outside their disciplinary areas and to support their institution in enhancing its social impacts. The diversity of student's areas of studies is very marked, suggesting that this is a transversal topic that interests students, whether they are involved in the social sciences or to more technical areas such as engineering or health.

The project represents an opportunity for students to address complex problems in HE with an approach that integrates the four archetypal models proposed by Zgaga (2009), that is, combining personal, professional, research-oriented and civic-political roles. As one participant student concluded "USR borders are much more wide and comprehensive" involving the HEI's "traditional commitment to the social tissue in forming a critical, visionary and sustainable generation" but permeating "the management of all University processes" (Male, UPorto).

We hope to present further updates on the data emerging fom this Project at future HEAd Conferences and a full account of the impact of the project on student participants at HEAd 2020 .

\section{References}

ABNT NBR ISO 26000 (2010). Diretrizes sobre responsabilidade social. 1a ed. 2010;

Centre for Good Governance (2005). Social Audit: Toolkit. Hyderabad: Jubilee Hills.

Chase, H. W. (1923). The social responsibility of the state university. Journal of Social Forces, 1 (5), 517-521.

Dewey, J. (1963). Experience \& Education. New York: Collier Books.

ESPRIT (2016). Enhancing the Social Characteristics and Public Responsibility in Israeli Teaching through an HEI-Student Alliance. European Commission. Available at: http://media.wix.com/ugd/1556f8_88a201993ebd4319b21035cf77f0ec4e.pdf

European Commission/EACEA/Eurydice (2015). The European Higher Education Area in 2015: Bologna Process Implementation Report. Luxembourg: Publications Office of the European Union.

EU-USR (2015). Comparative research on the Social Responsibility of Universities in Europe and development of a Community reference framework. Final report of the project EU-USR 52709-LLP-2012-1-RO-ERASMUS-ESIN. European Commission.

Fraser, N. (1998). Social Justice in the Age of Identity Politics: Redistribution, Recognition, Participation. Discussion Paper FS I 98 -108. Wissenschaftszentrum Berlin für Sozialforschung. Available at: https://www.econstor.eu/bitstream/10419/44061/1/269802959.pdf 
Gao, S. \& Zang, J. (2006). Stakeholder engagement, social auditing and corporate sustainability. Business Process Management Journal, 12 (6), 722-740.

Jain, S.P. \& Polman, W. (2003). A Handbook for Trainers on Participatory Local Development.. Thailand: FAO Regional Office for Asia and the Pacific. Available at: http://www.fao.org/docrep/006/AD346E/ad346e00.htm\#Contents.

Larrán, M.; López, A. Y. \& Márquez, C. (2011). La comunidad universitaria andaluza ante la responsabilidad social: un estudio de opinión. Foro de los Consejos Sociales de las Universidades Públicas de Andalucía.

Leichsenring, H. (2016). Universities cannot solve all the problems in the world. But they should try, in Global Access to Postsecondary Education. Brighton: University of Brighton;

London Communiqué (2007). Towards the European Higher Education Area: responding to challenges in a globalised world. Available at: http://www.ehea.info/articledetails.aspx?ArticleId=43 ;

Martin, B. (2016). University Social Responsibility: A common European Reference Frame work. Available at: www.eu.usr.eu ;

Schön, D. (1987). Educating the reflective practitioner. San Francisco CA: Jossey-Bass Inc., Publishers;

Williams, J. (2014). A critical exploration of changing definitions of public good in relation to higher education. Studies in Higher Education, 14(4) 619-630;

Zgaga, P. (2009). Higher education and citizenship: 'the full range of purposes'. European Educational Research Journal, 8 (2) 175-188. 